\title{
PENDIDIKAN EKONOMI INFORMAL: BAGAIMANA PENDIDIKAN EKONOMI MEMBENTUK PENGETAHUAN PADA BISNIS KELUARGA?
}

\author{
Muhammad Hasan \\ Pendidikan Ekonomi Universitas Negeri Makassar \\ Email: m.hasan@unm.ac.id
}

\begin{abstract}
This article examines aspects of knowledge transfer in family business that are implemented in informal economic education through Bandura's social cognitive theory model. This study uses literature studies by looking for theoretical references that are relevant to the case or problem found. The results of this study indicate that economic education forms knowledge in family business through the role of modeled behavior and will be studied in observational learning. The observational learning process itself is governed by four interrelated components, namely the process of attention, the process of retention, the process of motor reproduction, and the process of motivation.
\end{abstract}

Keywords: Economics education; informal eduction; knowledge transfer.

\begin{abstract}
Abstrak. Artikel ini mengkaji aspek transfer pengetahuan dalam bisnis keluarga yang terimplementasikan dalam pendidikan ekonomi informal melalui model teori sosial kognitif Bandura. Kajian ini menggunakan studi literatur dengan mencari referensi teori yang relevan dengan kasus atau permasalahan yang ditemukan. Hasil kajian ini menunjukkan bahwa pendidikan ekonomi membentuk pengetahuan dalam bisnis keluarga melalui peran perilaku yang dimodelkan dan akan dipelajari dalam pembelajaran observasional. Proses belajar observasional sendiri diatur oleh empat komponen yang saling terkait, yaitu proses perhatian, proses retensi, proses reproduksi motorik, dan proses motivasi.
\end{abstract}

Kata Kunci: Pendidikan ekonomi, pendidikan informal, transfer pengetahuan

\section{PENDAHULUAN}

Pentingnya peran bisnis keluarga dalam perekonomian suatu negara adalah fakta yang tak terbantahkan secara empirik (Basco, 2010; Musa dan Hasan, 2018). Studi di berbagai negara menunjukkan bahwa bisnis keluarga memainkan peran kunci dalam hal pertumbuhan ekonomi dan penciptaan lapangan kerja (Pistrui, et al., 2001; Anderson dan Reeb, 2003, Hasyim dan Hasan, 2017).

Dalam mengkaji keunikan dan karakteristik bisnis keluarga, para peneliti terutama yang menggunakan pandangan berbasis sumber daya telah memperkenalkan konsepkonsep seperti "familiness" (Habbershon dan Williams, 1999), "family capital" (Hoffman, Hoelscher dan Sorenson, 2006), "family effect" (Dyer, 2006) dan "family social capital" (Arrègle et al., 2007). Pandangan berbasis sumber daya berfokus pada usaha untuk mencapai keunggulan kompetitif dan berkelanjutan dari waktu ke waktu
(Penrose, 1959; Prahalad \& Hamel, 1990; Wernerfeldt, 1984) dan mengkaji sumber daya perusahaan idiosyncratic yang berkontribusi untuk mempertahankan keunggulan kompetitif (Barney, 1986, 1991). Sumber daya unik perusahaan keluarga berasal dari interaksi keluarga dan bisnis dan dianggap kompleks, dinamis, dan tidak berwujud (Habbershon dan Williams, 1999). Selain itu, dinyatakan bahwa karakterstik unik sumber daya perusahaan keluarga dapat menciptakan keuntungan, dan sebaliknya dapat pula menciptakan kerugian bagi bisnis keluarga (Sirmon dan Hitt, 2003).

Secara historis, modal, bahan mentah dan tenaga kerja dianggap lebih berharga daripada proses menciptakan dan menerapkan pengetahuan. Era informasi dan revolusi pengetahuan telah menyebabkan masalah bagi setiap individu dan organisasi (Hasan dan Azis, 2018; Dinar dan Hasan, 2018; Thamrin dan Hasan, 2018). Tuntutan dalam pengelolaan kecerdasan manusia dan mengubahnya menjadi produk dan layanan yang bermanfaat terus 
berkembang (Goffee dan Jones, 2000). Banyak organisasi menggunakan pengetahuan untuk meningkatkan pembelajaran dan pengalaman seseorang. Peluang untuk menggunakan pengetahuan adalah faktor utama dalam menarik dan mempertahankan tenaga kerja yang berbakat, loyal, produktif (Smith, 2000).

Pengetahuan adalah sumber keunggulan kompetitif dalam keluarga, sehingga proses transfer pengetahuan dalam bisnis keluarga merupakan hal yang menarik untuk dikaji. Transfer pengetahuan pada bisnis keluarga diimplementasikan dalam bentuk pendidikan ekonomi. Pendidikan ekonomi pada keluarga dilakukan baik secara formal, nonformal, maupun informal, dapat berkontribusi pada pengembangan sikap wirausaha, kemampuan dan keterampilan, sehingga berdampak pada efikasi diri dan meningkatkan motivasi berwirausaha, sehingga dapat disimpulkan bahwa transfer pengetahuan melalui pendidikan ekonomi dalam keluarga telah menawarkan wawasan yang berharga tentang bagaimana pendidikan ekonomi dapat membuat perbedaan dalam proses regenerasi pelanjut usaha dalam usaha kecil, khususnya yang terkait dengan sikap berwirausaha dan motivasi berwirausaha (Gibb, 2002; Mitra dan Matlay, 2004; Kuratko, 2005; Graevenitz, et al., 2010; Neck dan Greene, 2011; Hasan, 2016).

Saat ini lingkungan ekonomi menganggap bahwa pengetahuan ekonomi merupakan aspek yang sangat penting (Walstad, 1997; Blendon, et al., 1997; Gerardi, et al., 2010, Hasan, 2018). Karakter dan identifikasi pengetahuan ekonomi merupakan proses yang kompleks. Terdapat beberapa jenis pengetahuan (know-what, know-why, know-how and knowwho) yang dianggap penting dalam era ekonomi berbasis pengetahuan (Goetz dan Rupasingha, 2002; McGranahan dan Beale, 2002; Hasan, 2018).

Dalam era ekonomi klasik, pengetahuan tidak langsung diukur atau dimasukkan dalam fungsi produksi. Para peneliti berusaha menjelaskannya melalui bagian pertumbuhan ekonomi yang tidak terjelaskan. Bagian yang tidak dapat dijelaskan tersebut meliputi "faktor perubahan teknis", "faktor manusia", dan "faktor organisasi" (Abramowitz, 1956; Skilbeck, 1964). Dalam literatur ekonomi neoklasik, inovasi dan kewirausahaan dianggap sebagai unsur penting pertumbuhan ekonomi, hal tersebut dilihat dari pendapat Schumpeter yang menyatakan bahwa perubahan teknologi adalah mesin pertumbuhan ekonomi (Schumpeter, 1939). Berkaitan dengan pengetahuan baru untuk perubahan teknis, Antonelli (1998) mengemukakan bahwa generasi pengetahuan baru, dalam bentuk perubahan teknologi, dihasilkan dari interaksi antara generic knowledge (pengetahuan teknologi yang terkodifikasi secara ilmiah dan tacit knowledge (proses pembelajaran berdasarkan pengalaman dari inovator). Romer (1986; 1990) menganggap pengetahuan sebagai faktor penting ketiga dari produksi. Dalam masyarakat yang secara ekonomi-progresif, generic knowledge dan tacit knowledge bekerja secara bersama, sehingga pengetahuan ilmiah (generic knowledge) mengarah ke inovasi (tacit knowledge).

Artikel ini akan fokus untuk mengkaji aspek transfer pengetahuan dalam bisnis keluarga yang terimplementasikan dalam pendidikan ekonomi informal dan literasi ekonomi dalam bisnis keluarga yang diperoleh dari proses pendidikan ekonomi informal.

\section{METODE PENELITIAN}

Penelitian ini termasuk jenis penelitian studi literatur dengan mencari referensi teori yang relevan dengan kasus atau permasalahan yang ditemukan. Referensi teori yang diperoleh dengan jalan penelitian studi literatur dijadikan sebagai fondasi dasar dan alat utama bagi praktek penelitian selanjutnya (Munarfah dan Hasan, 2009).

Studi literatur adalah serangkaian kegiatan yang berkenaan dengan metode pengumpulan data pustaka, membaca dan mencatat, serta mengelolah bahan penelitian. Studi Literatur merupakan penelitian yang dilakukan oleh peneliti dengan mengumpulkan sejumlah buku dan artikel ilmiah yang berkaitan dengan masalah dan tujuan penelitian. Teknik ini dilakukan dengan tujuan untuk mengungkapkan berbagai teori-teori yang relevan dengan permasalahan yang sedang dihadapi/diteliti sebagai bahan rujukan dalam pembahasan hasil penelitian.

\section{HASIL DAN PEMBAHASAN}

Keluarga merupakan lembaga pendidikan yang pertama dan utama, sehingga keluarga diharapkan senantiasa berusaha menyediakan kebutuhan, baik biologis maupun psikologis bagi anak, serta merawat dan mendidiknya. Keluarga diharapkan mampu menghasilkan anak-anak agar dapat tumbuh menjadi pribadi yang dapat hidup ditengahtengah masyakatnya, dan sekaligus dapat menerima, menggunakan serta mewarisi nilai- 
nilai kehidupan dan kebudayaan. Keluarga merupakan kelompok inti karena keluarga adalah masyarakat pendidikan pertama yang bersifat alamiah (Roucek dan Warren, 1992).

Di dalam bisnis keluarga, terjadi transfer pengetahuan yang sifatnya antar generasi. Transfer pengetahuan tersebut terwujud dalam pendidikan ekonomi yang sifatnya informal. Bisnis keluarga adalah usaha yang dimiliki dan dikelola oleh setiap orang yang memiliki ikatan keluarga dan diharapkan dapat diwariskan ke generasi berikutnya (Chirico, 2008).

Dalam keluarga yang menjalankan bisnis, setiap orang tua (generasi pendahulu) memiliki harapan bahwa anak-anak mereka dapat melanjutkan kepemimpinan dalam bisnis keluarga (Trevinyo-Rodriguez \& Tapies, 2006). Namun meskipun demikian, terdapat pula pendahulu yang mengharapkan anak-anaknya memiliki karier yang lebih baik pada bidang pekerjaan lain yang lebih besar, dan ada juga pendahulu yang tidak memiliki ekspektasi apapun terhadap penerus. Berdasarkan hal tersebut, terlihat bahwa dalam proses alih generasi dalam bisnis keluarga, terdapat proses yang direncanakan, maupun proses yang tidak direncanakan.

Orang tua yang merencanakan transfer pengetahuan secara terencana memiliki skema yang sistematis dan memiliki tahapan yang jelas. Orang tua merencanakan kapan proses transfer tersebut dimulai dan tahapan-tahapan yang harus dilalui oleh penerus. Namun sebaliknya, orang tua yang tidak merencanakan proses transfer pengetahuan tidak memiliki tahapan dan waktu yang jelas dalam proses transfer pengetahuan.

Proses transfer pengetahuan yang terjadi dalam bisnis keluarga berimplikasi pada terjadinya proses pembelajaran dalam keluarga yang melibatkan orang tua sebagai generasi pendahulu dan anak sebagai generasi pelanjut. Bandura (1977), mengungkapkan bahwa manusia mempelajari sesuatu dengan cara meniru perilaku orang lain. Oleh karena itu, sebagian besar perilaku individu dipelajari oleh belajar observasional melalui imitasi pemodelan. Teori ini didasarkan pada fakta bahwa pengetahuan manusia didapat dari manusia lain. Dengan kata lain, hal-hal yang diketahui oleh anak atau generasi pelanjut dalam bisnis keluarga didasarkan oleh penjelasan yang diberikan oleh orang tuanya sebagai generasi pendahulu (Bandura, 1977; Yang dan Hsiang, 2001).

Teori kognitif sosial Bandura adalah perluasan dari teori behaviorisme yang menekankan pentingnya faktor perilaku, lingkungan, dan individu (kognitif) dalam proses pembelajaran (Bandura, 2012). Berdasarkan teori tersebut, perilaku dapat mempengaruhi kognitif dan sebaliknya aktivitas kognitif individu dapat mempengaruhi lingkungan, pengaruh lingkungan dapat mengubah proses pemikiran individu, dan sebagainya. Secara konseptual, proses pembelajaran sosial kognitif Bandura diilustrasikan pada Gambar 1.

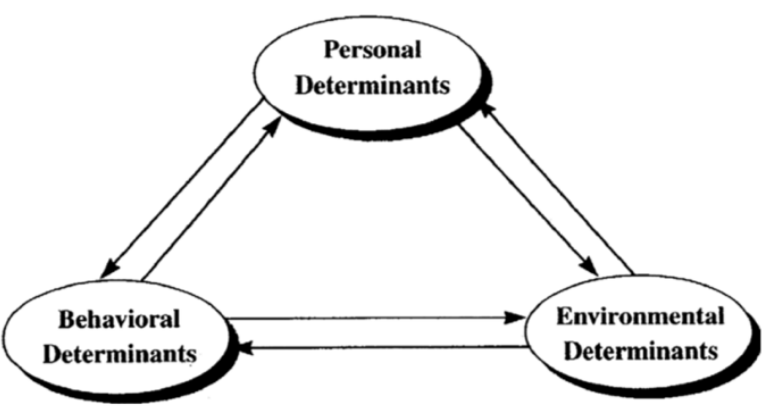

Gambar 1. Model Teori Sosial Kognitif (Bandura, 2012)

Proses pembelajaran kognitif sosial terjadi dalam tiga komponen, yaitu perilaku model, pengaruh perilaku model dan proses pembelajaran internal. Individu membuat proses belajar untuk mengenali perilaku model (perilaku yang ditiru), kemudian mempertimbangkan dan memutuskan untuk meniru dan menjadi perilaku mereka. Dalam hal ini, perilaku model dikenal sebagai perilaku di lingkungan. Jika perilaku model sesuai dengan situasi individu (minat, pengalaman, tujuan), maka perilaku model akan ditiru (Bandura, 2012). Dalam proses pembelajaran kognitif inilah terjadi proses transfer pengetahuan.

Model teori sosial kognitif, menunjukkan bahwa perilaku model di lingkungan individu terus memberikan atau mengeluarkan stimulus untuk reaksi dalam bentuk respons. Tanggapantanggapan ini yang nantinya akan dipelajari oleh individu melalui observasi (proses kognitif) terhadap perilaku yang ditunjukkan oleh model untuk meningkatkan minat individu terhadap sesuatu. Sedangkan minat itu sendiri hanya berarti sesuatu yang muncul menjadi perhatian atau keingintahuan seseorang. Oleh karena itu, individu awalnya mengamati (proses kognitif) lingkungan sekitar (sosial) secara selektif dan lebih lanjut mengingat (proses kognitif) perilaku kewirausahaan yang ditunjukkan oleh model. Diharapkan dengan melakukan kegiatan ini, individu dapat menciptakan minat dalam 
berwirausaha. Secara lebih detail, penjelasan proses pembelajaran kognitif sosial Bandura dengan cara observasi melalui peniruan perilaku model dalam kaitannya dengan minat individu dalam berwirausaha. Dalam proses inilah terjadi pembentukan literasi ekonomi melalui peran orang tua sebagai model.

Dalam konteks pendidikan ekonomi informal, transfer pengetahuan dalam bisnis keluarga dimulai dengan proses attentional (proses belajar kognitif pertama). Pada tahap ini, anak akan memperhatikan aktivitas kewirausahaan yang ditunjukkan oleh orang tua sebagai model. Proses ini membutuhkan keterlibatan anak, sehingga mereka harus bersama orang tua di tempat bisnis. Kegiatan yang diamati adalah kegiatan orang tua dalam menjalankan aktivitas bisnis di tempat usaha, misalnya, bagaimana perilaku orang tua ketika
Setelah proses mengamati dan mempertimbangkan, anak akan mengalami proses pembelajaran kedua yang disebut proses retensi. Aktivitas kewirausahaan yang ditunjukkan oleh orang tua sebagai model dan telah diamati dan dipertimbangkan oleh anak, akan disimpan lebih lanjut dalam memori dengan bentuk simbolis untuk diingat. Aktivitas kewirausahaan secara langsung di tempat bisnis, perlu ditunjukkan langsung oleh orang tua kepada anak di tempat bisnis karena anak dapat mengingat lebih baik ketika mengamati dan melakukan langsung aktivitas bisnis daripada hanya sekedar mendengarkan. Oleh karena itu, individu dalam proses ini terlibat langsung dalam bentuk pelatihan berwirausaha dan orang tua harus memberikan penjelasan yang sangat jelas dan detail untuk memfasilitasi anak dalam mengingatnya. Kegiatan semacam itu dapat



Gambar 2. Processes of Observational Learning (Bandura, 2001)

melakukan pembagian tugas pada karyawan, bagaimana orang tua menentukan harga barang, bagaimana perilaku orang tua dalam mengatur barang dagangan, bagaimana perilaku orang tua dalam menjual barang ke pasar, dan bagaimana perilaku orang tua dalam menata ulang barang yang memiliki telah terjual. Kegiatan-kegiatan yang dipamerkan oleh orang tua terutama yang berhubungan dengan pelanggan tidak hanya untuk didengar, tetapi harus diamati dan dipertimbangkan oleh individu sebagai pengalaman mereka sendiri (Hasan, 2018). berupa anak berpartisipasi untuk menghafal harga barang dagangan, terlibat dalam transaksi penjualan, terlibat dalam menata barang dagangan, serta terlibat dalam menentukan jenis dan jumlah barang yang akan dipesan kembali.

Selanjutnya, anak akan mengalami proses pembelajaran ketiga yang disebut proses reproduksi motorik. Dalam proses ini, anak menunjukkan kemampuan mereka dengan gerakan motorik persis meniru perilaku orang tua sebagai model dalam kaitannya dengan kegiatan kewirausahaan di tempat bisnis. Hal tersebut berarti bahwa anak telah mendapatkan 
keterampilan dan pelatihan kewirausahaan setelah mereka berlatih di tempat bisnis. Dalam proses ini, tanpa bantuan orang tua, anak dapat mengulangi berbagai aktivitas kewirausaha, seperti kegiatan dalam mengatur barang dagangan, mampu menghafal harga barang apa pun dengan menunjukkan kepada konsumen dengan benar, secara mandiri mampu menangani konsumen, dan mampu memesan dan menentukan barang yang diperlukan (Hasan, 2017).

Keberhasilan dalam imitasi yang ditunjukkan dalam perilaku nyata individu sangat tergantung pada proses belajar kognitif keempat yang disebut proses motivasi. Dalam proses ini, anak meniru perilaku orang tua sebagai perilaku mereka sendiri ketika anak termotivasi atau memiliki kemauan untuk melakukan aktivitas kewirausahaan dengan memberikan penguatan dan motivasi terhadap anak agar mereka menjadi tertarik dalam berwirausaha. Langkah ini disebut juga sebagai pengaturan diri yang mengacu pada proses di mana individu mengontrol dan mengarahkan kegiatan mereka.

Dalam konteks bisnis keluarga, pengetahuan dapat meningkatkan aset perusahaan (Pascarella, 1997). Pengetahuan adalah aset manusia, sangat pribadi dan mewakili keahlian yang dikumpulkan dan upaya jaringan dan aliansi. Fakta empirik menunjukkan bahwa hampir semua pekerjaan yang dilakukan orang adalah berdasarkan pengetahuan (Wah, 1999). Pengetahuan dalam bisnis keluarga didefinisikan sebagai kebijaksanaan dan keterampilan yang telah diperoleh dan dikembangkan oleh anggota keluarga melalui pendidikan dan pengalaman baik di dalam maupun di luar perusahaan (Chirico, 2008). Oleh karena itu, kemampuan yang harus disebarkan di seluruh anggota keluarga untuk bereksperimen dan mengembangkan sistem baru untuk menangkap dan mengumpulkan pengetahuan, dan pengalaman yang diperoleh oleh anggotanya (Comeche Martínez, 2007). Untuk CabreraSuárez, Saá-Pérez dan García-Almeida (2001) konsep pengetahuan dalam bisnis keluarga mencakup informasi kontekstual, pengalaman berbingkai, keyakinan, nilai dan wawasan ahli, serta pengetahuan dan keterampilan untuk melakukan tugas.

Keunggulan kompetitif perusahaan keluarga terutama didasarkan pada pengetahuan yang tertanam dalam sumber dayanya, dan terutama didasarkan pada pengalaman dan kemampuan pendahulunya. Pendahulunya merupakan sumber utama keterampilan dan kemampuan dalam organisasi, yang dapat membuat kehilangan pengetahuan jumlah ke perusahaan ketika ia pensiun. Dengan demikian, pengetahuan tacit pendiri adalah aset strategis yang harus ditransfer dan dikembangkan (Bracci, 2008).

Semakin pentingnya pengetahuan yang diperoleh menunjukkan kebutuhan untuk berpikir tentang bagaimana organisasi memproses basis pengetahuan mereka, yaitu, bagaimana organisasi menciptakan dan mengembangkan pengetahuan baru, dan bagaimana mereka berbagi dan mengirimkannya (Wong dan Aspinwall, 2004). Selain itu, pengetahuan hanya dapat dikembangkan dengan komunikasi dan menambah nilai melalui penggunaan, yaitu, pengetahuan berguna ketika dibagikan dan hanya memiliki nilai jika dipertukarkan (Zhang et al., 2008). Dengan demikian, transfer pengetahuan memberikan dasar bagi keunggulan kompetitif organisasi (Kumar \& Ganesh, 2009). Argote, Ingram, Levine, dan Moreland (2000) menunjukkan bahwa organisasi yang mampu mentransfer pengetahuan secara efektif dari satu unit ke unit lainnya, lebih produktif dan lebih mungkin bertahan daripada organisasi yang kurang efektif untuk mentransfer pengetahuan. Dengan demikian, sangat penting untuk memastikan kinerja dan pertumbuhan yang berkelanjutan (Brachos, Kostopoulos, Soderquist \& Prastacos, 2007; Zack, McKeen \& Singh, 2009; Chirico, Sirmon, Sciascia \& Mazzola, 2011, Hasan, 2014).

\section{SIMPULAN DAN SARAN}

Kajian tentang pengetahuan dan perilaku ekonomi individu sangat dinamis. Untuk memperoleh pengetahuan perilaku yang diharapkan, dibutuhkan proses belajar melalui pengalaman diri, belajar dari orang lain, dan belajar dari lingkungan sekitarnya. Proses pendidikan ekonomi informal yang diimplementasikan melalui proses transfer pengetahuan dari orang tua kepada anak dalam bisnis keluarga dibentuk melalui proses belajar. Pendidikan ekonomi informal yang dilakukan melalui proses pembelajaran kewirausahaan mengacu pada teori belajar kognitif sosial Bandura, merupakan kajian literatur penting khususnya berkaitan dengan peran keluarga dalam membentuk pengetahuan dan perilaku berwirausaha melalui transfer pengetahuan dari orang tua kepada anak. 
Bandura memandang tingkah laku manusia bukan semata-mata refleks otomatis dan stimulus melainkan juga akibat reaksi yang timbul sebagai hasil interaksi antara lingkungan dengan skema kognitif manusia itu sendiri. Teori belajar observasional, merupakan pembelajaran dengan cara melihat perilaku orang lain, atau model. Karena pendasarannya pada observasi terhadap orang lain-fenomena sosial-sudut pandang yang diambil oleh Bandura ini sering disebut dengan pendekatan kognisi sosial tentang belajar. Pembelajaran observasional adalah pembelajaran yang meliputi perolehan keterampilan, strategi dan keyakinan dengan cara mengamati orang lain. Melalui pembelajaran observasional diperoleh representasi kognitif dari pola perilaku lainnya, yang kemudian dapat berfungsi sebagai model untuk perilaku individu. Teori kognitif sosial menyatakan bahwa banyak dari kebiasaan cara kita menanggapi gaya kepribadian kita telah dipengaruhi oleh belajar observasional.

Pendidikan ekonomi membentuk pengetahuan dalam bisnis keluarga melalui peran perilaku yang dimodelkan dan akan dipelajari dalam pembelajaran observasional. Proses belajar observasional sendiri diatur oleh empat komponen yang saling terkait, yaitu proses perhatian, proses retensi, proses reproduksi motorik, dan proses motivasi. Dengan memahami empat komponen dalam proses belajar observasional, tampak bahwa pendekatan kognitif sosial telah membuat kontribusi penting dalam pendidikan ekonomi informal.

\section{RUJUKAN}

Abramowitz, M. 1956. Resource and Output Trends in The United States Since 1870, American Economic Review 46:5-23.

Antonelli, C. 1998. Localized Technological Change, New Information Technology and The Knowledge Based Economy: The European Evidence, Journal of Evolutionary Economics, 8:177-198.

Argote, L., Ingram, P., Levine, J., M., Moreland, R., L. 2000. Knowledge Transfer in Organizations: Learning from The Experience of Others. Organizational Behavior and Human Decision Processes, 82(1):1-8.

Arregle, J. L., Hitt, M. A., Sirmon, D. G., \& Very, P. 2007. The Development of Organizational Social Capital: Attributes of Family Firms, Journal of Management Studies 44(1), 73-95.

Bandura, A. 1977. Social Learning Theory. New Jersey. Prentice-Hall, Inc. A Paramount Communications Company. Englewood Cliiffs.

Bandura, A. 2001. Social Cognitive Theory: An Agentic Perspective. Annual Reviews Psychology, 52, 1-20.

Bandura, A. 2012. On the Functional Properties of Perceived Self-Efficacy Revisited, Journal of Management 38(1):9-44.

Barney J. B. 1986. Organizational Culture: Can It Be a Source of Sustained Competitive Advantage? Academy of Management Review, 11(3): 656-665.

Barney J. B. 1991. Firm Resources and Sustained Competitive Advantage, Journal of Management, 17(1): 99-120.

Basco, R. 2010. Tipo de orientación familiar y prácticas de dirección y gobierno. Un estudio aplicado a las empresas familiares españolas. Revista Europea de Dirección y Economía de la Empresa, 19(2): 129-144.

Blendon, R., J. Benson, M. Brodie, R. Morin, D. Altman, D. Gitterman, M. Brossard, and M. James. 1997. Bridging the Gap Between the Public's and Economists' Views of the Economy, Journal of Economic Perspectives, 11(3), 105-118.

Bracci, E. 2008. A Knowledge Framework for Understanding Small Family Business Succession Process. IUP Journal of Knowledge Management, Forthcoming.

Brachos, D., Kostopoulos, K., Soderquist, K., E., Prastacos, G. 2007. Knowledge Effectiveness, Social Context and Innovation. Journal of Knowledge Management, 11(5):31-44.

Cabrera-Suarez, K., Saa-Perez, P., GarciaAlmeida, D. 2001. The Succession Process from a Resource and Knowledge Based View of The Family Firm. Family Business Review, 14(1): 37-48.

Chalid Imran Musa, and Muhammad Hasan. 2018. The Influence of Social, Economic, and Demographic Characteristic on Working Hours of Micro, Small, and Medium Enterprises (MSMEs) in Makassar City, J. Phys.: Conf. Ser. 1028 012181.

Chirico, F. 2008. Knowledge Accumulation in Family Firms: Evidence from Four Cases 
Studies. International Small Business Journal, 26: 433-462.

Chirico, F., Sirmon, D., G., Sciascia, S., Mazzola, P. 2011. Resource Orchestration in Family Firms: Investigating How Entrepreneurial Orientation, General Involvement and Participative Strategy Affect Performance. Strategic Entrepreneurship Journal, 5(4):307326.

Comeche Martinez, J,. M. 2007. Influencia de los factores conductuales en la capacidad de acumulación, generación y transmisión de conocimientos en los entrepreneurial team de la organización en Decisiones basadas en el conocimiento y en el papel social de la empresa. $X X$ Congreso Anual de AEDEM, 1, 73.

Dinar, Muhammad, dan Hasan, Muhammad. 2018. Pengantar Ekonomi: Teori dan Aplikasi. Makassar: CV. Nur Lina Bekerjasama dengan Pustaka Taman Ilmu.

Dyer, W. G. Jr. 2006. Examining the Family Effect on Firm Performance, Family Business Review 19(4): 253-273.

Gerardi, K, L. Goette, and S. Meier. 2010. Financial Literacy and Subprime Mortgage Dilenquency: Evidence from a Survey Matched to Administrative Data, Federal Reserve Bank of Atlanta, Working Paper 2010-10.

Gibb, A. 2002. In Pursuit of a New Enterprise and Entrepreneurship Paradigm for Learning: Creative Destruction, New Values, New Ways of Doing Things and New Combinations of Knowledge, International Journal of Management Reviews, 4(3): 233-269.

Goffee, R. and Jones, G. 2000. Why should anyone be led by you?', Harvard Business Review, September- October, pp. 62-70.

Graevenitz, G., Harhoff, D., and Weber, R. 2010 The Effects of Entrepreneurship Education, Journal of Economic Behavior and Organization, 76(1): 90112.

Habbershon TG and Williams ML. 1999. A Resource-Based Framework for Assessing Strategic Advantages of Family Firms, Family Business Review, 12(1): 1-22.

Hasan, Muhammad. 2014. Produktivitas dan Elastisitas Kesempatan Kerja Sektor
Industri. Jurnal Economix Volume 2, No. 1 Desember 2014 ISSN 2302-6286. Makassar: Fakultas Ekonomi UNM.

Hasan, Muhammad. 2016. Pengembangan Pola Pendidikan Ekonomi Informal sebagai Upaya untuk Pembentukan Perilaku Ekonomi yang Baik, Prosiding Seminar Nasional "Mega Trend Inovasi dan Kreasi Hasil Penelitian dalam menunjang Pembangunan Berkelanjutan" hal. 82-87 Lembaga Penelitian Universitas Negeri Makassar. Makassar: Lembaga Penelitian UNM.

Hasan, Muhammad. 2017. Pendidikan Ekonomi Informal dan Literasi Keuangan, Prosiding Seminar Nasional "Membangun Indonesia Melalui Hasil Riset" hal. 677-680 Lembaga Penelitian Universitas Negeri Makassar. Makassar: Badan Penerbit UNM.

Hasan, Muhammad. 2018. Pembinaan Ekonomi Kreatif dalam Perspektif Pendidikan Ekonomi. Jurnal Ekonomi dan Pendidikan (JEKPEND) Volume 1, No. 1 Januari 2018 p-ISSN: 2614-2139; eISSN: 2614-1973.

Hasan, Muhammad, dan Azis, Muhammad. 2018.

Pembangunan Ekonomi \&

Pemberdayaan Masyarakat: Strategi

Pembangunan Manusia dalam Perspektif Ekonomi Lokal. Makassar: CV. Nur Lina Bekerjasama dengan Pustaka Taman Ilmu.

Hasyim, Hajerah, dan Hasan, Muhammad. 2017. Strategi Pemberdayaan dan Keunggulan Bersaing Industri Kecil, Prosiding Seminar Nasional Dies Natalis ke 56 Universitas Negeri Makassar. Makassar: Penerbit UNM.

Hoffman, James and Hoelscher, Mark and Sorenson, Ritch. 2006. Achieving Sustained Competitive Advantage: A Family Capital Theory, Family Business Review, Vol. 19, No. 2, pp. 135-145.

Kumar, J., A., Ganesh, L., S. 2009. Research on Knowledge Transfer in Organizations: a Morphology. Journal of Knowledge Management, 13(4): 161-174.

Kuratko, D., F. 2005. The Emergence of Entrepreneurship Education: Development, Trends and Challenges, Entrepreneurship, Theory and Practice, 29(5): 577-598.

Mitra, J and Matlay, H. 2004. Entrepreneurial and Vocational Education and Training: 
Lessons from Eastern and Central Europe, Industry \& Higher Education, 18(1): 5369.

Munarfah, Andi, dan Hasan, Muhammad. 2009. Metode Penelitian. Jakarta: CV. Pratika Aksara Semesta.

Neck, H., M and Greene, P., G. 2011 Entrepreneurship Education: Known Worlds and New Frontiers. Journal of Small Business Management, 49(1): 55-70.

Pascarella, P. 1997. Harnessing Knowledge, Management Review, October, pp. 37-40.

Penrose ET. 1959. The Theory of The Growth of The Firm. John Wiley \& Sons, New York.

Prahalad CK and Hamel G. 1990. The Core Competence of The Corporation, Harvard Business Review, 68(3): 79-91.

Romer, P. M. 1986. Increasing Returns and Long Run growth, Journal of Political Economy, 94(5):1002-37.

Romer, P. M. 1990. Endogenous Technological Change, Journal of Political Economy, 98(5):71-102.

Roucek, S. Joseph dan L. Warren, Rolland. 1992. Sociology An Introduction. America: United States.

Schumpeter, J. 1939. Business Cycles, Second Volume. New York: McGraw-Hill.

Smith, E., A. 2000. Applying Knowledge Enabling Methods in The Classroom and in the Workplace, Journal of Workplace Learning, 12(6), 236-44.

Sirmon DG and Hitt MA. 2003. Managing Resources: Linking Unique Resources, Management, and Wealth Creation in Family Firms, Entrepreneurship: Theory and Practice, 27(4): 339-358.
Skilbeck, M.1964. Study Group in the Economics of Education, Residual Factor and Economic Growth. Paris: Organisation for Economic Cooperation and Development.

Trevinyo-Rodriguez, R.N., Tapies, J. 2010. Effective Knowledge Transfer in Family Business. Working Paper-865. IESE. Business School of Navarra.

Wah, L. 1999. Making Knowledge Stick, Management Review, May, pp. 24-9.

Walstad, W. 1997. The Effect of Economic Knowledge on Public Opinion of Economic Issues, Journal of Economic Education, 28(3), 195-205.

Wernerfelt B. 1984. A Resource-Based View of The Firm, Strategic Management Journal, 5(2): 171-180.

Wong, K.,Y., Aspinwall, E. 2004. Characterizing Knowledge Management in The Small Business Environment. Journal of Knowledge Management, 8(3): 44-61.

Yang, F. K. and Hsiang, M. H. 2001. Development and Validation of Ethical Computer Self-Efficacy Measure: The Case of Softlifting. Journal of Business Ethics, Vol 32. P 299-315.

Zack, M., Mckeen, J., Singh, S. 2009. Knowledge Management and Organizational Performance: an Exploratory Analysis. Journal of Knowledge Management, 13(6):392-409.

Zhang, L., Zheng, X., Li, J., Nie, G., Huo, G., Shi, Y. 2008. A Way to Improve Knowledge Sharing: from the Perspective of Knowledge Potential. Journal of Service Science and Management, 1: 226-232 